Research Article

\title{
Evaluation of Anti-Urolithiatic Activity of Ethanolic Extract of Delonix regia Leaves in Experimental Animal
}

\author{
Dr. Sonali S Nipate*, Rajanigandha R Jori \\ Department of Pharmacology, PES's Modern College of Pharmacy, Nigdi, Pune, Maharashtra, India. \\ *Corresponding author's E-mail: sonynipate@rediffmail.com
}

Received: 14-11-2021; Revised: 20-01-2022; Accepted: 28-01-2022; Published on: 15-02-2022.

\section{ABSTRACT}

The aim of the present study was to investigate the anti-urolithiatic effect of Delonix regia leaves in ethylene glycol and ammonium chloride induced urolithiasis in wistar rats. Renal stone was induced in animals by $0.75 \%$ ethylene glycol and $1 \%$ ammonium chloride in drinking water for 28 days. In this study the test groups animals were administered with ethanolic extract of D.Regia at doses $200 \mathrm{mg} / \mathrm{kg}$ and $400 \mathrm{mg} / \mathrm{kg}$ once in day from 15 th day to 28 th day. Cystone $(75 \mathrm{mg} / \mathrm{kg})$ was used as standard drug. In this study in vitro crystallization is done by using nucleation assay and aggregation assay by using calcium chloride and sodium oxalate. The effect of Delonix regia on various physical and biochemical parameters in urine as well as serum was evaluated. The present study, results reveals that the administration of $400 \mathrm{mg} / \mathrm{kg}$ dose of Delonix regia reduced the biochemical parameter than $200 \mathrm{mg} / \mathrm{kg}$ and states that higher dose is an effective dose for treatment of urolithiasis.

Keywords: Anti-urolithiasis, Delonix regia, Ethylene glycol, Ammonium chloride.

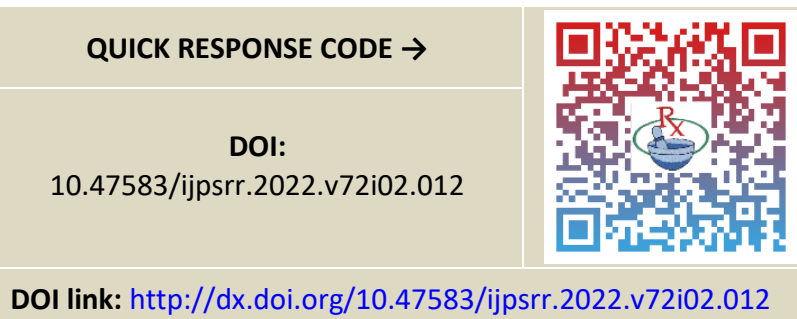

\section{INTRODUCTION}

U rolithiasis refers to the formation of stones in the urinary tract, including the kidney, ureter, and bladder. Urolithiasis is caused by the oversaturation of urine with stone-forming salts ${ }^{1}$. Nephrolithiasis, or kidney stone disease, is sometimes known as urolithiasis. A stone that grows to a diameter of more than 5 millimetres ( 0.2 inch) might clog the ureter, causing significant pain in the lower back or belly. The majority of stones develop as a result of a mix of hereditary and environmental factors. High urine calcium levels, obesity, some diets, some drugs, and calcium supplementation are all risk factors. Symptoms, urine testing, and medical imaging are commonly used to make the diagnosis. Blood testing may be beneficial as well. Nephrolithiasis (stones in the kidney), ureterolithiasis (stones in the ureter), and cystolithiasis (stones in the bladder) are the most common classifications (calcium oxalate, uric acid, struvite, cystine) is what they are formed of ${ }^{2}$. Amongst there were many different sorts of stones, but the most prevalent were calcium oxalate stones. Several factors contribute to the formation of stones. Crystallization is the first step in a series of physicochemical events nucleation, growth, and aggregation are all processes that occur within the body. Urogenital tract it's a major medical issue that affects people all around the world. About $12 \%$ of the population is affected, which is three times more than the national average. Men are more likely than women to have this condition ${ }^{3}$. Urolithiasis recurrence rates are roughly $10 \%$ after one year, $33 \%$ after five years, and $50 \%$ after ten years ${ }^{4}$. The mechanisms involved in the production of stone calcification are not completely understood. Anatomic, environmental, genetic, metabolic, dietary, and socioeconomic factors all play a role in its etiopathogenesis 5 . Citrate is an inhibitor, and low urine volume, calcium, oxalate, uric acid, phosphate, and other promoters are promoters, and the imbalance between them could be a cause in lithogenesis. Urinary calculi can induce obstruction, hydronephrosis, infection, urinary tract bleeding, hypertension, tubular necrosis, and subsequent kidney fibrosis, resulting in cell injury and renal stone reformation ${ }^{6}$. Combinations of medicinal and surgical procedures are frequently used to treat urolithiasis. Stone removal techniques include endoscopic stone removal and extracorporeal shock wave lithotripsy. These treatments are both expensive and painful, and they have a number of negative side effects, including haemorrhage, hypertension, tubular necrosis, and eventual fibrosis of the kidney, which leads to cell injury. Stone recurrence is also fairly prevalent ${ }^{7}$. To prevent the recurrence of hypercalciuria and hyperoxaluria-induced calculi, thiazide diuretics and alkali-citrate are employed, however scientific proof for their usefulness is lacking. As a result, novel pharmacological therapy is needed that is cost-effective, targets several etiological risk factors in urolithiasis, and reduces the rate of recurrence ${ }^{8}$.

Since ancient times, medicinal plants have played a significant role in the treatment of numerous diseases in India's traditional medicine. For the bulk of the world's population, the plants provide a low-cost supply of pharmaceuticals. Phytotherapeutic drugs could be 
employed as an alternative or supplemental therapy in the treatment of urolithiasis, according to in vitro and in vivo data ${ }^{9}$.

Delonix regia is an Indian medicinal plant which belongs to family Fabaceae which is native to Madagascar. This tree distributed in various regions of India, Africa, and North Australia. In many tropical parts of countries around the world it is grown as an ornamental tree and in an English, it is given the name Royal Poinciana or Flamboyant. It is also known as Flame tree ${ }^{10}$. The plant contains rich in tannins, flavonoids, saponins, sterols and organic Acids. The leaves of plant are used for bronchitis, and pneumonia in infants, anti- diabetic, gastric problems and rheumatic joints pain. The present work is carried out on phytopharmacological survey of the plant. The objective of the present study was to investigate the presence of various phytochemicals from the hydro alcoholic extract of Delonix regia. The extraction contains alkaloids, saponins, glycosides, tannins, flavonoids. Delonix regia is known as Gulmohar or the Flame tree. The tree reaches upto 40 feet height with the red orange flowers. The flowers are large, with four spreading scarlet or orange-red petals upto $8 \mathrm{~cm}$ long, and a fifth upright petal called the standard, which is slightly larger and spotted with yellow and white. Seedpods are dark brown and can be up- to $60 \mathrm{~cm}$ long and $5 \mathrm{~cm}$ wide; the individual seeds, however, are small, weighing around $0.4 \mathrm{~g}$ on average ${ }^{10}$. According to literature survey Delonix regia shows diuretic activity because of the presence of flavonoids and it may be responsible for the anti-urolithic activity.

\section{MATERIAL AND METHOD}

\section{Plant Material}

The leaves of Delonix regia were collected in the month of December from the local area of Shirur, Pune, Maharashtra, India. This plant was identified and authenticated by the Botanical survey of India, Pune (No. BSI/WRC/Iden. Cer./ 2021/1903210002847)

\section{Preparation of Extract}

The leaves of Delonix regia were collected and dried and shade and powdered and stored in air tight container. The dried powder macerated with $(2000 \mathrm{ml})$ of $95 \%$ ethanol for 10 days with occasional shaking. The extract then filtered off and dried at room temperature to prevent loss of important plant constituents then to obtain a crude ethanolic extract of Delonix regia (yield-10g) ${ }^{11}$.

\section{Chemicals}

Calcium chloride, sodium oxalate, ammonium chloride, Ethylene glycol was purchase from (Research-lab Fine Chem Industries Mumbai 400002.India), (Loba Chem pvt Ltd, 107, Wodehouse Road, Mumbai 400005.India) Cystone Tablet $(750 \mathrm{mg} / \mathrm{kg}$ ) (The Himalaya Drug Company, Bangalore, India). All the chemicals and reagents were used of analytical grade.

\section{Experimental animals}

Healthy male Wistar rats (150-200g) were procured from Global Bioresearch Solution Pune. Animals were housed in a group of 6 per cage in standard polypropylene cages lined with raw husk. The animals were kept in a temperaturecontrolled room $\left(22 \pm 2^{\circ} \mathrm{C}\right)$ with relative humidity $65-70 \%$. All experimental procedures were carried out in accordance with the guidelines prescribed by committee for the purpose of control and supervision on experiments on animals i.e. CPCSEA (884/PO/Re/S/05/CPCSEA) were approved by institutional animal ethics committee (IAEC).

\section{Ethylene glycol and ammonium chloride induced urolithiasis}

Rats were divided into 5 groups of six animals each $(n=6)$. Calcium oxalate stones were induced in rats by administering $0.75 \% \mathrm{v} / \mathrm{v}$ of Ethylene glycol (EG) and $1 \%$ $\mathrm{w} / \mathrm{v}$ of Ammonium chloride (AC) in drinking water for 15 days ${ }^{12}$.

The treatment schedule was planned as follows:

Group I: Normal (untreated) (Water For 28 Days)

Group II: Disease control (EG + AC in drinking water for 28 days)

Group III: Standard (EG + AC + cystone $750 \mathrm{mg} / \mathrm{kg}$, orally from day $15^{\text {th }}$ to $28^{\text {th }}$ )

Group IV: Treatment (EG + AC + Delonix regia 200 mg/kg, orally from day $15^{\text {th }}$ to $28^{\text {th }}$ )

Group V: Treatment (EG +AC + Delonix regia $400 \mathrm{mg} / \mathrm{kg}$, orally from day $15^{\text {th }}$ to $28^{\text {th }}$ )

\section{Assessment of Anti-Urolithiatic Activity}

\section{In-Vitro activity}

\section{Nucleation Assay}

Nucleation assay was used to determine inhibitory effect of Delonix regia on calcium oxalate crystals by spectrometric method. In this study, crystallization was initiated by adding calcium chloride $(5 \mathrm{mmol} / \mathrm{L})$ and sodium oxalate $(7.5 \mathrm{mmol} / \mathrm{L})$ solutions, which were prepared in a Tris Buffer $(0.05 \mathrm{~mol} / \mathrm{L})$ and sodium chloride $(0.15 \mathrm{~mol} / \mathrm{L})$ at $\mathrm{pH} 6.5 .1 \mathrm{ml}$ of extract solution of Delonix regia $(200 \mathrm{mg} / \mathrm{kg}, 400 \mathrm{mg} / \mathrm{kg}$ ) was mixed with $2 \mathrm{ml}$ calcium chloride solution followed by addition of sodium oxalate solution. The rate of nucleation of crystals was determined by comparing the induction time of crystals in the presence of the extract and without extract. The absorbance (optical density, OD) was recorded at $620 \mathrm{~nm}$ in UV visible spectrophotometer. The percentage inhibition was calculated as using under mentioned formula ${ }^{13}$.

\section{Aggregation Assay}

The calcium oxalate monohydrate crystals were prepared by mixing solutions of sodium oxalate and calcium chloride at $50 \mathrm{mmol} / \mathrm{L}$, heated to $60^{\circ} \mathrm{C}$ in a water bath for one hour and then incubated overnight at $37^{\circ} \mathrm{C}$. The calcium oxalate 
crystals were dissolved in Tris buffer $(0.05 \mathrm{~mol} / \mathrm{L})$ and sodium chloride $(0.15 \mathrm{~mol} / \mathrm{L})$ at $\mathrm{pH} 6.5 .1 \mathrm{ml}$ of extract solution $(200 \mathrm{mg} / \mathrm{kg}, 400 \mathrm{mg} / \mathrm{kg})$ was mixed with $2 \mathrm{ml}$ calcium oxalate solution and absorbance was recorded at $620 \mathrm{~nm}$ at interval of $0,30,60,90 \mathrm{~min}$. The percent inhibition of aggregation was estimated as described in the nucleation assay ${ }^{13}$.

\section{Collection and analysis of urine}

All animals were housed in individual metabolic cages for 24 hours after 28 days of calculi inducing therapy, and urine samples were collected. Uric acid, urea, creatinine, calcium, oxalate, magnesium, and phosphate were all measured in the urine samples. The urine samples were also utilised to investigate crystalluria by examining them under a microscope for the presence of calcium oxalate crystals ${ }^{14}$.

\section{Collection and analysis of blood}

Blood was taken from the retro-orbital plexus under light anaesthesia on the 28th day. Uric acid, urea ${ }^{15}$, creatinine ${ }^{16}$, and blood urea nitrogen were all measured in the serum (BUN).

\section{Histopathology}

Animals were sacrificed after blood and urine samples were collected, and both kidneys were identified, removed, and kept in a specimen jar containing $10 \%$ formalin for histological investigation. As a damage index, histological alterations such as necrosis, haemorrhages, congestion were detected.

\section{Statistical analysis}

The data were analysed using Graph pad prism software. The results were analysed by One way ANOVA followed by Dunett's Multiple Comparison test. All results were expressed as mean \pm standard error of mean (SEM). Differences between groups were considered significant at $\mathrm{p}<0.05$.

\section{RESULTS}

\section{In-Vitro analysis}

\section{Nucleation Assay}

When urine becomes supersaturated, calcium oxalate crystals form in the urinary tract. The first step in the formation of crystals is nucleation. As a result of the crystal growth and agglomeration, the process is known as crystal aggregation. As standards, citric acid and hydrochloric acid were used. D. Regia (200 mg/kg and $400 \mathrm{mg} / \mathrm{kg}$ ) prevents crystallisation by preventing calcium oxalate nucleation and disintegration into smaller particles. Fig 1 it shows that D. Regia exhibit nucleation preventing activity.

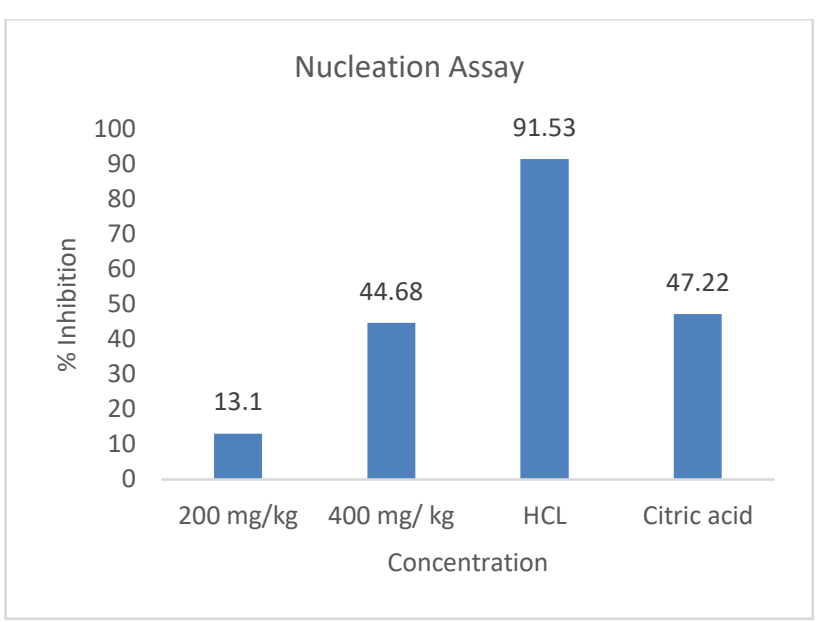

Figure 1: Nucleation assay shows, extract of D. Regia $(200 \mathrm{mg} / \mathrm{kg}$ and $400 \mathrm{mg} / \mathrm{kg})$ against citric acid and hydrochloric acid at absorbance $620 \mathrm{~nm}$.

\section{Aggregation Assay}

D. Regia was compared to citric acid and hydrochloric acid, both of which inhibit crystal aggregation and so prevent the formation of calcium oxalate crystals. At absorbance $620 \mathrm{~nm}$, (fig. 2) indicates prevention of calcium oxalate crystal aggregation at $0,30,60$, and 90 minutes.

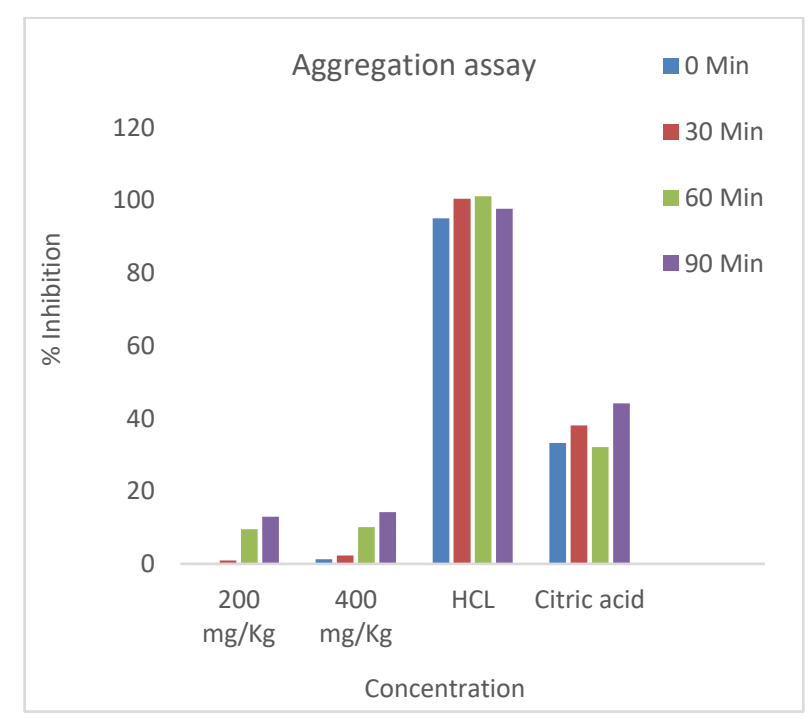

Figure 2: Aggregation assay shows, extract of D. Regia $(200 \mathrm{mg} / \mathrm{kg}$ and $400 \mathrm{mg} / \mathrm{kg}$ ) against citric acid and hydrochloric acid at absorbance $620 \mathrm{~nm}$.

\section{In- Vivo analysis}

\section{Effect of Delonix regia on urine analysis}

Various urolithiatic promoters such calcium, oxalate, magnesium, phosphate, uric acid, urea, and creatinine were examined in the urine. The urinary excretion of urolithiatic promoters in the urine of illness control rats was significantly higher than that of normal control rats. When compared to urolithiatic control rats, treatment of D. Regia $200 \mathrm{mg} / \mathrm{kg}$ and $400 \mathrm{mg} / \mathrm{kg}$ results in a significant reduction in urine excretion of calcium, oxalate, magnesium, phosphate, uric acid, urea, and creatinine. The urolithiatic promoters 
are reduced more when $D$. Regia is given at a higher dose $(400 \mathrm{mg} / \mathrm{kg})$. These findings were compared to those of the conventional medication. Cystone also shows significant reduction on urolithiatic parameters.

Table 1: Effect of D. Regia extract on Calcium, Magnesium, Oxalate, Phosphate level in ethylene glycol \& ammonium chloride induced urolithiatic model of rats.

\begin{tabular}{|c|c|c|c|c|c|}
\hline Group & Treatment & Calcium $(\mathbf{m g} / \mathbf{d L})$ & Magnesium $(\mathbf{m g} / \mathrm{dL})$ & Oxalate $(\mathrm{mg} / \mathrm{dL})$ & Phosphate $(\mathrm{mg} / \mathrm{dL})$ \\
\hline I & Normal Control & $0.1250 \pm 0.0118$ & $29.99 \pm 0.4255$ & $2.805 \pm 0.2269$ & $2.857 \pm 0.2291$ \\
\hline II & Disease Control & $1.907 \pm 0.1151 \# \# \#$ & $19.57 \pm 0.574 \# \# \#$ & $8.60 \pm 0.245 \# \# \#$ & $8.272 \pm 0.2939 \# \# \#$ \\
\hline III & Cystone $(750 \mathrm{mg} / \mathrm{kg})$ & $1.540 \pm 0.03864 * *$ & $21.23 \pm 0.5318$ & $7.798 \pm 0.2045$ & $8.025 \pm 0.3337$ \\
\hline IV & DR $(200 \mathrm{mg} / \mathrm{kg})$ & $1.015 \pm 0.0483^{* * *}$ & $23.59 \pm 0.359 * * *$ & $7.368 \pm 0.222^{* *}$ & $7.240 \pm 0.1480 *$ \\
\hline V & DR $(400 \mathrm{mg} / \mathrm{kg})$ & $0.6340 \pm 0.087 * * *$ & $25.81 \pm 0.463 * * *$ & $6.00 \pm 0.220^{* * *}$ & $5.862 \pm 0.2935 * * *$ \\
\hline
\end{tabular}

All of the data obtained from the experimental groups have been compared with disease control and normal control groups. The data was analyzed statistically by one-way ANOVA followed by Dunnett test using Graph pad prism. Values are significant at $* \# p<0.05 . * * \# p<0.01, * * * \# \# \#<<0.001 . *$ Comparison of disease control group with standard group and all test group. \# Comparison of normal control group with disease group, standard group and all test group.

Table 2: Effect of D. Regia extract on Uric Acid, Urea, Creatinine level in ethylene glycol \& ammonium chloride induced urolithiatic model of rats.

\begin{tabular}{|c|c|c|c|}
\hline Experimental Groups & Uric Acid $(\mathbf{m g} / \mathbf{d L})$ & Urea $(\mathbf{m g} / \mathbf{d L})$ & Creatinine $(\mathbf{m g} / \mathbf{d L})$ \\
\hline Normal Control & $3.803 \pm 0.3470$ & $20.20 \pm 0.3364$ & $27.34 \pm 1.307$ \\
\hline Disease Control & $8.015 \pm 0.3884 \# \# \#$ & $27.07 \pm 0.4926 \# \# \#$ & $34.28 \pm 0.9327 \# \#$ \\
\hline Cystone $(750 \mathrm{mg} / \mathrm{kg})$ & $7.910 \pm 0.4030$ & $25.75 \pm 0.5707$ & $31.10 \pm 1.272$ \\
\hline DR $(200 \mathrm{mg} / \mathrm{kg})$ & $6.895 \pm 0.2868$ & $25.16 \pm 0.3756^{*}$ & $30.28 \pm 1.173$ \\
\hline DR $(400 \mathrm{mg} / \mathrm{kg})$ & $6.240 \pm 0.3434^{* *}$ & $24.54 \pm 0.4524^{* *}$ & $29.70 \pm 1.416 *$ \\
\hline
\end{tabular}

All of the data obtained from the experimental groups have been compared with disease control and normal control groups. The data was analyzed statistically by one-way ANOVA followed by Dunnett test using Graph pad prism. Values are significant at $* \# p<0.05 . * * \# p<0.01, * * * \# \#$. ${ }^{*}<0.001 . *$ Comparison of disease control group with standard group and all test group. \# Comparison of normal control group with disease group, standard group and all test group.

\section{Effect of D. Regia on blood analysis}

Urolithiasis induction impairs renal function, resulting in elevated levels of uric acid, urea, creatinine, and blood urea nitrogen in the blood. The serum uric acid, urea, creatinine, and blood urea nitrogen levels are significantly reduced when D. regia $(200 \mathrm{mg} / \mathrm{kg}$ and $400 \mathrm{mg} / \mathrm{kg}$ ) is combined with ethylene glycol and ammonium chloride. When compared to disease control, treatment with a greater dose of $D$. regia $(400 \mathrm{mg} / \mathrm{kg})$ and cystone results in a reduction in blood indicators.

Table 3: Effect of D. Regia extract on Uric Acid, Urea, Creatinine, Blood urea nitrogen (BUN) level in ethylene glycol \& ammonium chloride induced urolithiatic model of rats.

\begin{tabular}{|c|c|c|c|c|}
\hline Experimental Groups & Uric Acid $(\mathrm{mg} / \mathrm{dL})$ & Urea $(\mathbf{m g} / \mathbf{d L})$ & Creatinine $(\mathbf{m g} / \mathbf{d L})$ & BUN $(\mathbf{m g} / \mathbf{d L})$ \\
\hline Normal Control & $3.272 \pm 0.2440$ & $41.87 \pm 0.5584$ & $0.3733 \pm 0.03955$ & $9.030 \pm 0.4269$ \\
\hline Disease Control & $9.737 \pm 0.608 \# \#$ & $49.57 \pm 1.531 \# \# \#$ & $1.200 \pm 0.1015 \# \# \#$ & $20.11 \pm 0.7085 \# \# \#$ \\
\hline Cystone $(750 \mathrm{mg} / \mathrm{kg})$ & $8.085 \pm 0.191^{* *}$ & $46.32 \pm 0.6635$ & $1.010 \pm 0.09532$ & $18.40 \pm 0.8118$ \\
\hline DR $(200 \mathrm{mg} / \mathrm{kg})$ & $7.253 \pm 0.148^{* * *}$ & $43.47 \pm 0.776^{* * *}$ & $0.7900 \pm 0.04919^{* *}$ & $18.06 \pm 0.7072$ \\
\hline DR $(400 \mathrm{mg} / \mathrm{kg})$ & $6.088 \pm 0.1611^{* * *}$ & $41.26 \pm 0.767^{* * *}$ & $0.5800 \pm 0.04050^{* * *}$ & $17.02 \pm 0.4675^{* *}$ \\
\hline
\end{tabular}

All of the data obtained from the experimental groups have been compared with disease control and normal control groups. The data was analyzed statistically by one-way ANOVA followed by Dunnett test using Graph pad prism. Values are

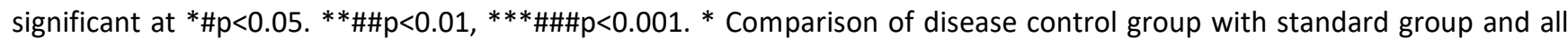
test group. \# Comparison of normal control group with disease group, standard group and all test group. 


\section{Microscopic analysis of urine}

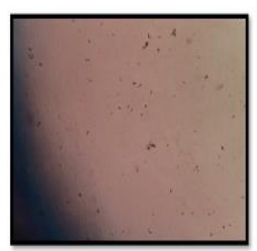

A) Normal Control

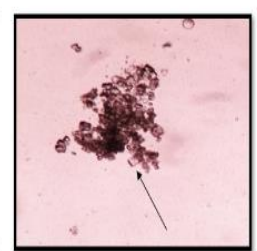

B) Disease control

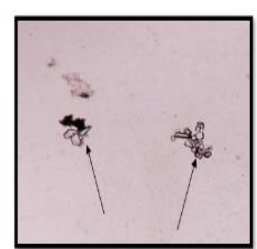

C) Standard Control(Cystone 750 $\mathrm{mg} / \mathrm{Kg}$ )

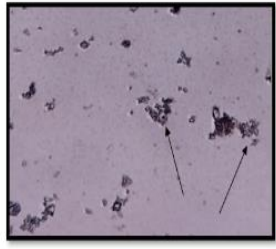

D) D.Regia (200 mg/Kg)

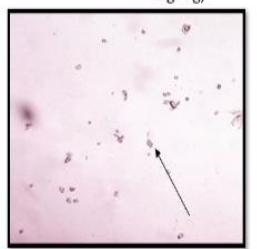

E) D.Regia $(400 \mathrm{mg} / \mathrm{Kg})$
Figure 3: Microscopy of urine

Urine microscopic examination Calcium oxalate accumulation in urolithiatic induced animals is seen in the (fig. 3) When compared to urolithiatic control, the standard medication Cystone demonstrates a reduction in calcium oxalate crystals. Treatment with D. Regia $(200 \mathrm{mg} / \mathrm{kg}, 400 \mathrm{mg} / \mathrm{kg})$ prevents stone formation by preventing the accumulation, deposition, and supersaturation of stone-forming components. It also has a diuretic effect, which helps to drain out tiny stones from the kidneys. A higher dose of D. Regia $(400 \mathrm{mg} / \mathrm{kg}$ ) was more effective in lowering the risk of stone formation and shrinking the size of the crystals.

\section{Histopathology of kidney}

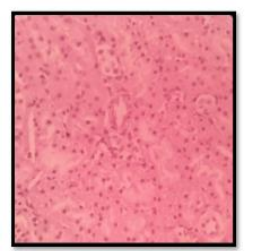

A) Normal Control

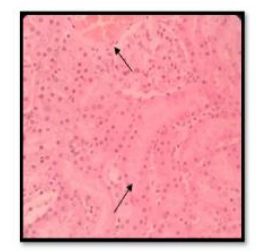

B) Disease control

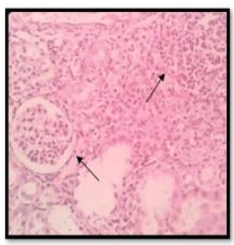

C) Standard Control(Cystone 750 $\mathrm{mg} / \mathrm{Kg}$ )

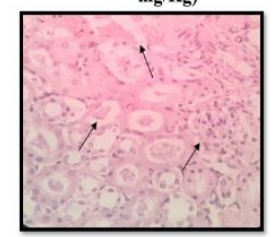

E) D.Regia $(400 \mathrm{mg} / \mathrm{Kg})$
Figure 4: Histopathology of kidney

In normal control animals, histopathological studies reveal normal kidney tissue structure. Calculi-induced animals kidneys showed significant histological alterations, including a rise in the damage index, glomerular inflammation, cloudy tubules. In the kidneys of calculiinduced mice, necrosis, tubule dilatation, and interstitial inflammation were found. In rats treated with $D$. Regia $(200 \mathrm{mg} / \mathrm{kg}$ and $400 \mathrm{mg} / \mathrm{kg})$ with cystone, all of these histological alterations and damage index were dramatically reduced like glomerular inflammation and cloudy tubules in the kidneys of rats treated with D. Regia $(200 \mathrm{mg} / \mathrm{kg}$, $400 \mathrm{mg} / \mathrm{kg})$.

Fig. 4 Microscopic images of kidney sections by trinocular microscope (100x). Normal control (A) showing intact structure with Bowman's capsule and blood vessels. Disease control (B) showing interstitial inflammation with congested blood vessels. Standard control (C) showing degenerative changes in tubular epithelial cells, dilated and congested blood vessels. D. Regia $(200 \mathrm{mg} / \mathrm{kg}$ ) (D) showing normal cellularity with less congested blood vessels and reduction in glomerular inflammation. D. Regia $(400 \mathrm{mg} / \mathrm{kg})$ (E) showing normal cellularity, intact structure with Bowman's capsule and normal blood vessels.

\section{DISCUSSION}

Urinary supersaturation with respect to stone forming agents or constituents are the important factors responsible for the formation of stone or calculogenesis.

In-vitro crystallization and in-vivo experimental animal models using wistar rats have been used to study urolithiasis.

In in-vitro crystallization, nucleation is an important step for the initiation of crystals, those crystals grow and form aggregates.

The result of the nucleation assay shows that the extract contained nucleation preventing agents. The extract contains a component that inhibits the formation of calcium oxalate crystals, according to the results of the aggregation assay.

The biochemical mechanism of ethylene glycol and ammonium chloride induced urolithiasis are related to an increase in the urinary concentration of oxalate. Ethylene glycol was administered to rats along with ammonium chloride, as it acidifies the urine and then accelerates the process of lithiasis. Hence, Ethylene glycol and Ammonium chloride in drinking water were employed to induce calcium oxalate urolithiasis in rats. So, by using this model we can evaluate the anti-urolithiatic activity of ethanolic extract $D$. regia on calcium oxalate urolithiasis ${ }^{17,18}$.

To induce urolithiasis, male rats are selected because testosterone plays an important role in oxalate production which increases serum testosterone level in male rats thereby, liver increases endogenous production of oxalate and further low concentration of ethylene glycol and ammonium chloride solution induces calcium oxalate urolithiasis in male rats, similar results were not produce in females that is why male rats are more susceptible to develop calcium oxalate crystals than female rats ${ }^{19}$.

According to literature survey treatment with $D$. regia increases urine volume due to diuretic effect which decreases the saturation of salts and prevents the precipitation of the crystals at physiological $\mathrm{pH}$.

In calculi-induced animals, there were an increase in urine volume. Due to the diuretic effect of $D$. regia, which reduces calcium oxalate supersaturation in urine and thus 
reduces stone formation, treatment with $D$. regia also increases urine volume, but less than calculi-induced animals ${ }^{10}$.

Increased urinary calcium causes the nucleation and precipitation of calcium oxalate in the urine, which leads to crystal formation. In this study, both the extract and Cystone $(750 \mathrm{mg} / \mathrm{Kg})$ dosages showed a decrease in urine calcium as compared to the disease control group. Reduced level of calcium in urine allows less calcium to bind with oxalate, resulting in reduction of crystals, as shown in urinary microscopy 2021.

In evaluation of urine analysis, the magnesium test is required because the low level of magnesium is responsible for stone formation which observed in diseased control group.

In the case of crystallisation, magnesium acts as a urinary inhibitor. Magnesium form complex with oxalate and reduced the supersaturation of calcium oxalate by reducing the growth and nucleation of crystals. In this study, magnesium level was restored to near normal levels after treatment with D.regia, and crystal formation was reduced. A higher dose of extract $(400 \mathrm{mg} / \mathrm{kg})$ causes an increase in magnesium levels in the urine ${ }^{22}$.

Increased urinary phosphate excretion combined with oxalate stress creates an ideal environment for stone development by producing calcium phosphate crystals, which then trigger calcium oxalate crystal deposition. In urinary Phosphate analysis, D.regia treatment reduces the rate of urinary phosphate excretion, which reduces the formation of stones ${ }^{23}$.

In case of urolithiasis GFR decreases due to the obstruction of flow of urine. As the GFR greatly decreases, the nitrogenous waste products like urea, creatinine, BUN, and uric acid get accumulated in blood.

An increase in nitrogenous substances in urine such as uric acid, urea and creatinine are the indicators for kidney and tubular damage. Treatment with D. regia which shows the significant decrease in nitrogenous substances because diuretic action is need to increase the amount of fluid going through the kidneys and flush out deposits.

After treatment with D. regia, there is an improvement in GFR due to reduction in kidney tissue injury and inflammation. The use of a higher dose of $D$. Regia $(400 \mathrm{mg} / \mathrm{kg})$ results in a decrease in urine nitrogenous compounds. Ethylene glycol and ammonium chloride induces nephrotoxicity in urolithiasis, which is characterized by a significant increase in serum uric acid, serum urea, serum creatinine, and blood urea nitrogen (BUN).

D. Regia treatment minimizes the accumulation of nitrogenous compounds in the blood, lowers nephrotoxicity, and improves GFR. The amount of nitrogenous waste products is reduced when the extract dose is increased.
In lithiatic animals, microscopic analysis of kidney sections reveals Glomerular inflammation, cloudy tubules, Interstitial inflammation, congested blood vessels, and damaged glomerulus. However, treatment with test extract resulted in significant improvements, particularly in animals given a high dose of test extract 24 .

\section{CONCLUSION}

The current study backs up the usage of D. Regia in folk medicine to treat urolithiasis. The administration of $D$. Regia whole plant extract reduced and prevented the formation of urinary stones, according to the findings. It also appears that the preventative benefit outweighs the curative treatment. As a result, D. Regia leaves extract is effective in preventing disease recurrence. The mechanism behind this action is mediated by diuretic, antioxidant, and nephroprotective effects, as well as reducing urinary stone-forming ingredient concentrations.

\section{REFERENCES}

1. Vyas. N, Kesearvani R. K., Jain.S, Raghuvanshi R., and Gavatia N. P., "Urolithiasis and its management," Der Pharmacia Lettre, 2010; vol. 2, no. 1: pp. 457-466.

2. Litwin MS, Saigal CS (eds.). Urologic Diseases in America (NIH Publication No. 07-5512). Bethesda, Maryland: National Institute of Diabetes and Digestive and Kidney Diseases, National Institutes of Health, United States Public Health Service, United States Department of Health and Human Services. Archived (PDF) from the original on 18 October 2011; pp. 283-319.

3. Deorao M.A, Vaishali M, Shanti P.B, Sharda P.C. Antilithiatic effect of Achyranthu saspera Linn. leaves extract on ethylene glycol induced nephrolithiasis. J Pharm Res 2009; 2(5): 994-7.

4. Doddametikurke R.B, Biyani C.S, Browning A.J, Cartledge J.J. The role of urinary kidney stone inhibitors and promoters in the pathogenesis of calcium containing renal stones. EAU-EBU Update Ser 2007; 5: 126-36.

5. Alessandra C.P, Elvino JGB, Dietary calcium intake among patients with urinary calculi, Nutr Res 2003; 23: 1651-60.

6. Terlecki R.P, Triest J.A, A contemporary evaluation of the auditory hazard of extracorporeal shock wave lithotripsy, Urology 2007; 70: 898-9.

7. Bouanani S, Henchiri C, Migianu-Griffoni E, Aouf $N$, Lecouvey M. Pharmacological and toxicological effects of Paronychia argentea in experimental calcium oxalate nephrolithiasis in rats. J Ethnopharmacology 2010; 129: 3845.

8. Pak C.Y. Prevention and treatment of kidney stones. Role of medical prevention. J Urol 1989; 141: 798-801.

9. Barros M.E, Lima R, Mercuri L.P, Matos J.R, Schor N, Boim MA, et al. Effect of extract of Phyllanthus niruri on crystal deposition in experimental urolithiasis. Urol Res 2006; 34: 351-7.

10. Jaynthi M.k, Amoghimath.S, To evalute the diuretic acivity in ethanolic extract of leaves of Delonix regia in wistar albino rats. Biomedical \& Pharmacology Journal, June 2018; Vol-11(2): p. 959-963. 
11. Mariajancyrani J. In-Vitro Antioxidant Potential of Delonix regia Leaves et al., Sch. Acad. J. Pharm., 2013; 2(6): 468471

12. Atmani $F$, Slimani $Y$, Mimouni $M$, Hacht B. Prophylaxis of calcium oxalate stones by Herniaria hirsuta on experimentally induced nephrolithiasis in rats. BJU Int 2003; 92: 137-40

13. Patel P.K, Patel M.A, Vyas B.A, Shah D.R, Gandhi TR. Antiurolithiatic activity of saponin rich fraction from the fruits of S. xanthocarpum schard \& wendl (Solanaceae) against ethylene glycol induced urolithiasis in rats journal of ethnopharmacology 144 (2012); Pg No 160-170.

14. Khan A, Bashir S, Khan SR, Gilani AH, Antiurolithic activity of Origanum vulgareis mediated through multiple pathways, BMC Complementary Altern Med 2011; Pg.No 11: 96.

15. Lequang N.T, Migueres G, Roche D, Pelladeau M.L, Labrousse $F$, Improved dye procedure for determining urea concentration by using o-phthalaldehyde and naphthyl ethylenediamine, Clin Chem 1987; Pg.No 33(1): 192.

16. Bowers L.D, Kinetic serum creatinine assays I. The role of various factors in determining specificity. Clinical Chem 1980; Pg No26(5): 551-4.

17. Scheid C.R, Cao L.C, Honeyman T, Jonassen J.A. How elevated oxalate can promote kidney stone disease: changes at the surface and in the cytosol of renal cells that promote crystal adherence and growth. Front Biosci 2004; 9: Pg. No797-808.
18. Thamilselvan S, Khan S.R, Menon M. Oxalate and calcium oxalate mediated free radical toxicity in renal epithelial cells: effect of antioxidants. Urol Res 2003; Pg No 31: 3-9.

19. Karadi R.V, Gadge N.B, Alagawadi K.R, Savadi R.V. Effect of Moringa oleifera Lam. Root-wood on ethylene glycol induced urolithiasis in rats. J Ethnopharmacology 2006; Pg No 105: 306-11.

20. Divakar K, Pawar A.T, Chandrasekhar S.B, Dighe S.B, Divakar G. Protective effect of the hydro-alcoholic extract of Rubia cordifolia roots against ethylene glycol induced urolithiasis in rats. Food Chem Toxicology 2010; Pg No 48: 1013-8.

21. Bashir S, Gilani A.H. Antiurolithiatic effect Bergenio ligulata rhizome: an explanation of the underlying mechanisms. J Ethnopharmacology 2009; 122: 106-16.

22. Selvam R, Kalaiselvi $P$, Govindaraj A, Murugan V.M, Satishkumar A.S. Effect of A. lanata leaf extract and Vediuppu chunnam on the urinary risk factors of calcium oxalate urolithiasis during experimental hyperoxaluria. Pharmacology Res 2001; 43: 89-93.

23. Soundararajan $\mathrm{P}$, Mahesh R, Ramesh $\mathrm{T}$, Begum VH. Effect of Aerva lanata on calcium oxalate urolithiasis in rats. Ind J Exp Biol 2006; 44: 981-6.

24. Guruvayoorappan C, Afira AH, Kuttan G. Antioxidant potential of Biophytum sensitivum extract in vitro and in vivo. J Basic Clin Physiology Pharmacology 2006; 17: 25567

Source of Support: The author(s) received no financial support for the research, authorship, and/or publication of this article.

Conflict of Interest: The author(s) declared no potential conflicts of interest with respect to the research, authorship, and/or publication of this article.

For any question relates to this article, please reach us at: globalresearchonline@rediffmail.com New manuscripts for publication can be submitted at: submit@globalresearchonline.net and submit_ijpsrr@rediffmail.com 